\title{
EQCM study of copper and iron corrosion inhibition in presence of organic inhibitors and biocides
}

\author{
J. Telegdi *, A. Shaban, E. Kálmán \\ Hungarian Academy of Sciences, Chemical Research Center, Institute of Chemistry, Pusztaszeri út 59-67, Pf: 17, \\ H-1525 Budapest, Hungary
}

Received 17 August 1999; received in revised form 14 December 1999

\begin{abstract}
Attention has been devoted to the application of quartz crystal microbalance (QCM) in the field of corrosion and corrosion inhibition. In-situ measurements were performed on copper and iron surfaces. Copper corrosion inhibition by the application of several inhibitors was followed by QCM. Copper corrosion inhibition in different electrolyte solutions such as acidic sodium sulphate and neutral sodium chloride were investigated. Different inhibitor compounds were tested for protection against copper corrosion. Three different groups of inhibitors were investigated; aromatic sulfoxides, benzo-hydroxamic acid derivatives, and azole derivatives. Among the tested sulfoxides, di-benzyl-sulfoxide (DBSO) produced the best protection, while $p$-chloro-benzo-hydroxamic acid showed excellent protection among the benzo-hydroxamic acid derivatives. Among the tested azole derivatives, 5-mercapto-1-phenyl-tetrazole (5-McPhTT) and 5-(4'-isopropylbenzylidene)-2,4-dioxotetrahydro-1,3-thiazole (5-IPBDT) showed excellent inhibition properties against copper corrosion in acidic media. The effect of biocides, namely $N$-hydroxyalkylated amino acids, on biofilm formation has been investigated, too. From the attained results, it is clear that QCM is an essential tool for obtaining important information on corrosion inhibition and its mechanism. (C) 2000 Elsevier Science Ltd. All rights reserved.
\end{abstract}

Keywords: Quartz crystal microbalance; Copper corrosion; Corrosion inhibition; Biocides; Microbially induced corrosion (MIC)

\section{Introduction}

Interfacial processes at electrode surface require utilization of sophisticated techniques in order to obtain detailed information on structure and composition of interfaces. Quartz crystal microbalance (QCM) is one of the novel methods applied in the field of electrochemical interfaces.

QCM consists of a thin quartz crystal blade sandwiched between two metal electrodes, which produce an alternating electric field across the crystal, causing vibrational motion of the crystal at its resonant frequency

\footnotetext{
* Corresponding author.
}

[1]. This resonant frequency is sensitive to mass changes of the crystal and its deposited electrodes. One major advantage of QCM is its applications in an electrochemical cell, where it is referred to as electrochemical quartz crystal microbalance (EQCM).

The high sensitivity of quartz crystal microbalance is the basis for its application in thin film studies. In addition, interfacial processes can be measured on a time scale of $\approx 100 \mathrm{~ms}$, with the exact time scale depending on the frequency counter used [2]. The ultimate time resolution of EQCM is fundamentally limited by the time required for equilibrium of the device with the deposited mass, which depends upon the operating frequency and the quality factor of the electrochemical quartz crystal microbalance [1,2]. 
Mass losses result in frequency increase and vice versa. The resonance frequency for a quartz crystal in a liquid is affected by several factors, such as, resonance frequency, frequency shift caused by mass change due to surface layers (deposition, adsorption, etc.), and frequency shift caused by the damping influence of the liquid.

EQCM was often used as an ex situ technique to sense mass changes at electrode surfaces during and after some processes (such as electrodeposition or dissolution of metals) [3]. Several research groups developed in situ electrochemical quartz crystal mass sensors [47].

Electrochemical dissolution of metal films can be examined conveniently by EQCM [8-11]. Such investigations have obvious relevance to the use of piezoelectric transducers as corrosion sensors.

\subsection{Applications in corrosion inhibition}

Several research groups investigated the inhibition effect of some chemical substances, as potential inhibitors, by EQCM. Pickering and his research group [12] studied copper corrosion inhibition in neutral environment by using the benzotriazole-acid- $\mathrm{Na}_{2} \mathrm{SO}_{4}$ system, but some frequency shifts could not be explained. Hepel [13] utilized EQCM to observe the effect of benzotriazole (BTA) on the copper corrosion rate in composite poly-pyrole-copper film. EQCM was also applied in the studies of corrosion inhibition in neutral media where the protective films are more complex and several processes take place at the same time. Trabanelli et al. [14] studied the inhibition properties of some heterocyclic compounds in $\mathrm{NaCl}$ solution, using EQCM.

In our investigations, attention was focused on the effectiveness determination of several potential inhibitor molecules in different $\mathrm{pH}$ ranges. In acidic solutions aromatic sulfoxides (di-benzyl-sulfoxide (DBSO), di-phenyl-sulfoxide (DPSO), di-p-tolyl-sulfoxide (DPTSO)), tetrazole derivatives (5-mercapto-1phenyl-tetrazole (5-McPhTT)), and thiazole derivatives (5-benzylidene-2,4-dioxo tetrahydro-1,3-thiazole (5BDT) and 5-(4'-isopropylbenzylidene)-2,4-dioxotetrahydro-1,3-thiazole (5-IPBDT)) were examined. In neutral media the following benzohydroxamic acid (BHA) derivatives were tested: ortho-chloro-benzo-hydroxamic acid (o-Cl-BHA), para-chloro-benzo-hydroxamic acid ( $p$-Cl-BHA), para-nitro-benzo-hydroxamic acid $(p-\mathrm{N}-$ BHA), and $o$-methyl benzo-hydroxamic acid (o-MBHA)

\subsection{Application in $M I C$}

Microorganisms play an important role in deterioration and degradation of materials, especially in aqueous environment. They can attach to surfaces and form gelatinous films. Planktonic population is less dangerous than the sessile population. Biofilms influence surfaces, liquid phase, and the interfacial processes which results in contamination water systems [15], reduction of heat transfer [16] and negative influence on implanted devices [17].

Interaction between bovine cells and proteins responsible for cell adhesion was detected by QCM. The time-course of the frequency decrease reflected the strength of cell adhesion onto protein coated QCM.

Gryte et al. [18] demonstrated that QCM is a viable technique for monitoring anchorage-dependent cell attachment and detachment on surfaces. Nivens et al. [19] monitored the attachment and surface growth of the Pseudomonas cepacia by QCM in long-time, on-line experiments.

In aquatic systems, aerobic and anaerobic microorganisms deteriorate metallic substrates. The role of microbes in corrosion processes is mainly due to their metabolisms associated with microbial growth and reproduction. In the presence of microbes biofilm formation begins immediately after exopolymeric substance excretion and cell adhesion. The microbial colonization markedly modifies the corrosion behavior of metallic substrata. Corrosion-relevant microbes exaggerate the deterioration not only by the adhesion and aggressive metabolites excretion but also by the formation of concentration cells and diffusion barriers.

Several papers appeared on bacterial adhesion but little attention was given to the use of QCM in monitoring biocidal activity on biofilm formation. As the local attack of the microbes attached to the metal surface causes the most severe problem, our experiments were aimed at controlling adhesion at an early stage.

Chemicals that control microbial activity are called biocides. Beside inhibiting microbial activities, biocide must be environmentally acceptable. Biocides can influence microbial growth and proliferation as well as inhibit metabolic processes, exopolysaccharide production and the accumulation of cells on surfaces. As biocides control different processes in microbiologically influenced corrosion (MIC), parallel techniques were used to elucidate certain steps of inhibition. Microbiological and electrochemical experiments provided information on the effect of biocides on bacterial multiplication and metabolite excretion. As biofilms influence surface chemistry, interfacial and liquid phase, QCM was used to study bacterial adhesion and its inhibition by biocides.

In our experiments, QCM (with gold and iron layers) was applied to quantitatively detect microbial adhesion and determine influence of biocides on bacterial attachment. 


\section{Experimental}

\subsection{Electrolytes}

Reagent grade chemicals and distilled water were used to prepare the following electrolytes:

- $0.1 \mathrm{M} \mathrm{Na}_{2} \mathrm{SO}_{4}$ at $\mathrm{pH}=2.95$

- $0.1 \mathrm{M} \mathrm{Na}_{2} \mathrm{SO}_{4}, \mathrm{pH}=2.95$, containing $5 \times 10^{-4} \mathrm{M}$ of tested sulfoxides.

- $0.1 \mathrm{M} \mathrm{Na}_{2} \mathrm{SO}_{4}, \mathrm{pH}=2.95$, containing $5 \times 10^{-4} \mathrm{M}$ 5-McPhTT.

- $0.1 \mathrm{M} \mathrm{Na}_{2} \mathrm{SO}_{4}$ at $\mathrm{pH}=2.95$, containing $1 \times 10^{-5} \mathrm{M}$ 5-BDT.

- $0.1 \mathrm{M} \mathrm{Na}_{2} \mathrm{SO}_{4}$ at $\mathrm{pH}=2.95$, containing $1 \times 10^{-5} \mathrm{M}$ 5-IPBDT.

- $0.5 \mathrm{M} \mathrm{NaCl}$ at $\mathrm{pH}=6.5$.

- $0.5 \mathrm{M} \mathrm{NaCl}$ at $\mathrm{pH}=6.5$, containing $1 \times 10^{-3} \mathrm{M}$ of BHA tested derivatives.

\subsection{Experimental procedure}

The quartz crystal used was an AT-cut disk of 12 $\mathrm{mm}$ diameter and of $10-\mathrm{MHz}$ nominal oscillation frequency. At both sides, gold was deposited over a thin layer of chromium. An assembly, which consisted of a Potentiostat, (Model PS-205, ELCHEMA, NY, USA) and an Electrochemical Quartz Crystal Nanobalance, (Model EQCN-700, ELCHEMA, NY, USA), was used for QCM measurements. The program waveform was generated by VOLTSCAN Real-Time Data Acquisition System (Intellect Software, NY, USA). SCE and platinum plate were used as reference and counter electrodes, respectively. Frequency changes, which were converted to mass changes, of the quartz electrode, were registered in time at open circuit potential.

Copper was electrodeposited from an acidic copper bath containing $0.5 \mathrm{M} \mathrm{CuSO}_{4}, 0.5 \mathrm{M} \mathrm{H}_{2} \mathrm{SO}_{4}$, and $1 \mathrm{M}$ $\mathrm{C}_{2} \mathrm{H}_{5} \mathrm{OH}$. The freshly deposited copper electrode was washed thoroughly with distilled water. Then the aggressive solution was immediately added to the cell. For experiments performed on iron surfaces, the layers were electrodeposited from a deposition bath containing 0.9 $\mathrm{M} \mathrm{FeSO}+4.17 \mathrm{M} \mathrm{Al}_{2}\left(\mathrm{SO}_{4}\right)_{3}$.

Measurements in acidic media were performed in three intervals: in interval I (3000 s), the applied solution was a blank $0.1 \mathrm{M} \mathrm{Na}_{2} \mathrm{SO}_{4}$, then in interval II (10 $000 \mathrm{~s})$, the solution was exchanged for an inhibitor containing electrolyte, and finally in interval III (7000 s), the solution was re-changed for aggressive solution used in interval I.

Measurements in neutral media $(0.5 \mathrm{M} \mathrm{NaCl})$ were done in separate runs for the blank solution and the inhibitor containing solutions. Each experiment was performed for a time interval of $30000 \mathrm{~s}$. the electrode was freshly deposited for each investigation.

In biofilm experiments, $50 \mathrm{ml}$ of cooling water (mixed population: $5 \times 10^{5} / \mathrm{cm}^{3}$ ) was used in all experiments with or without biocides ( $N$-hydroxyalkylated amino acids in cooling water, $100 \mathrm{ppm}, \mathrm{pH}=$ 7).

In blank experiments, after removal of microbes by filtration, influence of biocides on viscosity and density was determined. All biofilm experiments were adjusted by the blank experiment results. Experiments time interval was $6000 \mathrm{~s}$ on gold surface. Biofilm formation rate was determined on freshly deposited iron surfaces, too.

Chemicals used as biocides were Q-CH(NH$\left.\mathrm{CH}_{2} \mathrm{OH}\right) \mathrm{COOH}$ where Q represents the chains listed below:

\begin{tabular}{ll}
\hline Abbreviation of biocides & $\mathrm{Q}$ \\
\hline NHMAla & $\mathrm{CH}_{3}$ \\
NHMAbu & $\mathrm{CH}_{3} \mathrm{CH}_{2}$ \\
NHMNva & $\mathrm{CH}_{3} \mathrm{CH}_{2} \mathrm{CH}_{2}$ \\
NHMSer & $\mathrm{HO}-\mathrm{CH}_{2}$ \\
NHMAsp & $\mathrm{HOOC}-\mathrm{CH}_{2}$ \\
NHMGlu & $\mathrm{HOOC}_{-} \mathrm{CH}_{2} \mathrm{CH}_{2}$ \\
NHMPhy & $\mathrm{C}_{6} \mathrm{H}_{5}$ \\
NHMPhe & $\mathrm{C}_{6} \mathrm{H}_{5} \mathrm{CH}_{2}$ \\
NHMTyr & $\mathrm{HOC}_{6} \mathrm{H}_{4} \mathrm{CH}_{2}$ \\
NHMHys & $\mathrm{C}_{3} \mathrm{H}_{3} \mathrm{~N}_{3}$ \\
\hline
\end{tabular}

\section{Results and discussions}

\subsection{Corrosion inhibition studies}

Several studies have assumed preset values for the quartz crystal sensitivity constant $\left(C_{\mathrm{f}}\right)$, depending on crystal type and nominal frequency. This value is very important in converting frequency changes into mass. During our measurements, a calibration plot of frequency change versus time was constructed during copper electrodeposition as can be seen in Fig. 1. Using Sauerbrey's equation [1], frequency change is related to mass change which is calculated from Faraday's law, thus producing $C_{\mathrm{f}}$. Since nearly no current loss occurs under the deposition conditions, the amount of deposited metal $(\Delta m)$ is:

$\Delta m=\frac{M_{\mathrm{W}} \cdot i \cdot n \cdot \Delta t}{2 \cdot F}$

where $i$ is the current density applied; $M_{\mathrm{W}}$, is the copper atomic weight; $n$, is the number of electrons involved, and $F$ is Faraday's constant. 
The electrode potential was also monitored and used as an indicator of surface coverage. Stable potential is an indication of total coverage.

During acidic media experiments, the mass change due to dissolution could be expressed as thickness reduction rate, which is more practical for estimating the corrosion damage:

$\ddot{\delta}=\frac{\Delta m}{\mathrm{~A} \cdot \rho \cdot t}$

where $\delta$, is the thickness reduction rate; $\rho$, is the copper density; $A$, is the electrode active area, and $\Delta m$, is the mass loss.

\subsection{Corrosion inhibition dependence on $\mathrm{pH}$}

EQCM was applied in studying several potential copper corrosion inhibitors in different electrolyte solution.

The inhibition efficiencies of several aromatic sulfoxides in acidic $0.1 \mathrm{M} \mathrm{Na}_{2} \mathrm{SO}_{4}$ were investigated using the EQCM method. In interval I, frequency measurements of different inhibitors showed some deviation in the rate of frequency change, which is explained by deviation in surface state, such as roughness and/or oxide layers, during copper deposition (Fig. 2a, b and c). Because of surface roughness deviation from one experiment to another, corrosion rates are assumed as average values [11].

Inhibitor effectiveness, thorough corrosion rate calculations, can be monitored at any time. Of the sulfoxides tested, DBSO produced the best inhibition efficiency as depicted in Fig. 2. This thin layer hinders copper corrosion even in the absence of inhibitor in the solution, as can be seen in interval III of Fig. 2.

Based on Eq. (2), thickness reduction rate for cases involving aromatic sulfoxides were calculated and tabulated in Table 1.

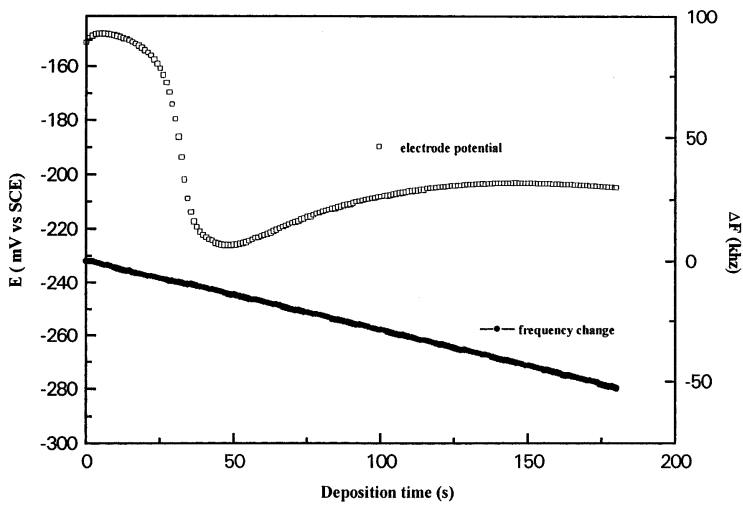

Fig. 1. Calibration curve of frequency change, due to copper electrodeposition, and potential change versus time, to determine quartz crystal sensitivity coefficient.
The effectiveness of 5-McPhTT against copper corrosion in $0.1 \mathrm{M} \mathrm{Na}_{2} \mathrm{SO}_{4}$ was investigated. The addition of 5 -McPhTT clearly modified and hindered copper corrosion in acidic media (Fig. 3). QCM measurements showed that a 2-D type layer is formed on copper surface. The slight increase in electrode mass is a result of inhibitor adsorption, as can be seen in Fig. 3. Inhibitor adsorption is persistent even in the absence of the inhibitor in the electrolyte.

The addition of 5-IPBDT produced slight better protection, against copper corrosion, than 5-BDT (Fig. 4). This fact can be due to the presence of isopropyl group in 5-IPBDT structures, providing longer chain, which serves as an umbrella protecting the electrode surface. The prolonged affect of 5-IPBDT, which could be due to chemical adsorption on the copper surface, was more efficient than that of 5-BDT. The thickness reduction rate results are tabulated in Table 2 .

The inhibition effect of modified benzo-hydroxamic acids on copper corrosion in neutral environment was also investigated. Different substituents showed different contributions to the inhibition efficiency. Fig. 5 shows the behavior of copper electrode in the absence and presence of BHA derivatives, measured by EQCM. Comparison between $o$-Cl-BHA and $p$-Cl-BHA shows the influence of substituent position on the inhibition effect. As ortho and para positions are equivalent from the aspect of hydrophobic characters, the improved inhibition of $p$-Cl-BHA is not only due to delocalized electron distribution but also due to elongated chlorobenzo chain.

Mass decrease can be regarded as total mass loss in the early corrosion stage. A relationship between mass loss (ML) and exposure time can be derived. The curve for blank solution reveals a parabolic relationship between mass loss and exposure time, which can be described by $\mathrm{ML}=R \sqrt{t}$. This representation suggests that copper dissolution process follows a transport-limited mechanism, the rate of which is determined by copper diffusion. This behavior is clearly identified in the case of copper in $0.5 \mathrm{M} \mathrm{NaCl}$. In case of solutions containing inhibitors, such as $p$-Cl-BHA, corrosion films, formed on the electrode, grow according to an asymptotic law. This suggests that film growth, in inhibitor containing solutions, is of an impervious passive complex layer, which hinders diffusion. The strong decrease in copper dissolution in the presence of $p-\mathrm{Cl}-$ $\mathrm{BHA}$, is due to the protective power of the complex film formed.

\subsection{Results of biofilm experiments}

Biocides are supposed to influence microbial growth, multiplication, the excretion of exopolymeric substances (EPS) and the production of aggressive metabolites. Chemicals that decrease the EPS production will 

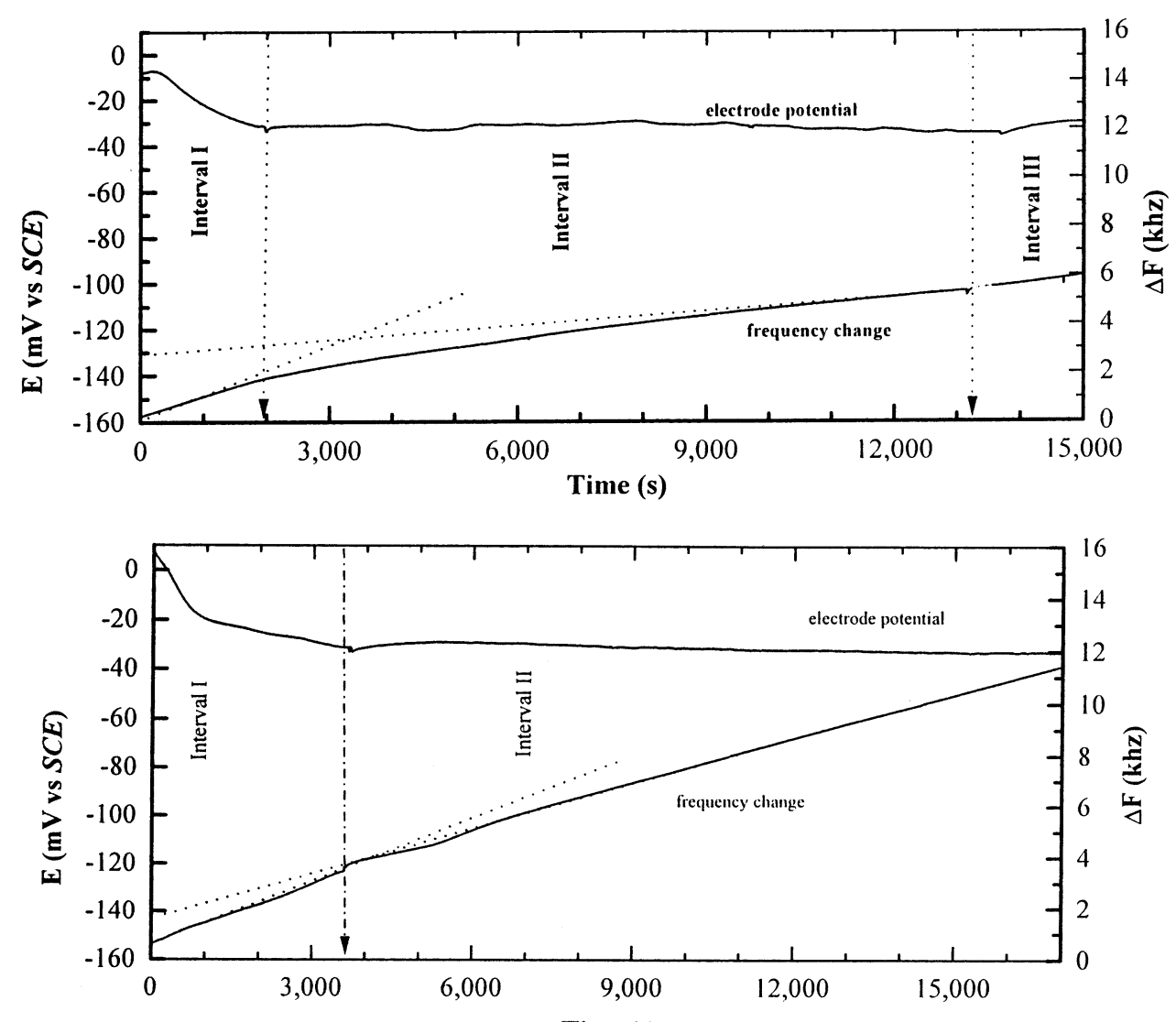

Time (s)

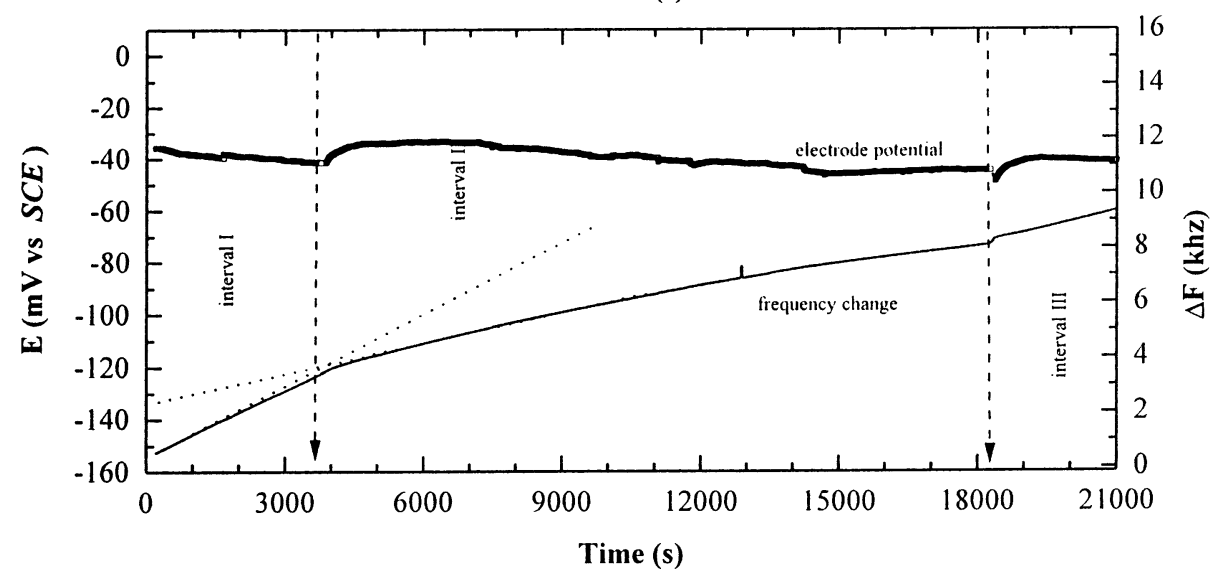

Fig. 2. Time dependence of mass and electrode potential of copper electrode in $0.1 \mathrm{M} \mathrm{Na}_{2} \mathrm{SO}_{4}$ (pH 2.95). (a) In the absence and presence of DBSO; (b) in the absence and presence of DPSO; (c) in the absence and presence of DPTSO.

decrease the microbial deterioration too as mainly the sessile population is dangerous from corrosion point of view.

Microbial growth and propagation inhibited by $N$ hydroximethylated series of amino acids (with systematically changed structure) was monitored by different techniques such as gravimetric and microbial methods in order to obtain quantitative information on different phases of MIC. The substituted amino acids inhibited microbial proliferation by two to three orders of magnitude which depended on the side chain of the amino acids.

The quartz crystal microbalance can monitor the cell attachment and the inhibition of the adhesion by different additives sensitively. These chemicals already showed biocidal efficiency on planktonic/sessile and 
Table 1

Thickness reduction rate of copper electrode in $0.1 \mathrm{M} \mathrm{Na}_{2} \mathrm{SO}_{4}$ ( $\mathrm{pH} 2.95$ ), with and without the addition of different sulfoxides

\begin{tabular}{|c|c|c|c|c|}
\hline \multirow[t]{2}{*}{ Sulfoxide } & \multicolumn{3}{|c|}{ Thickness reduction rate $(\mu \mathrm{m} /$ year $)$} & \multirow[t]{2}{*}{ IE $(\%)$} \\
\hline & Interval I & Interval II & Interval III & \\
\hline DBSO & 710 & 152 & 314 & 78 \\
\hline DPSO & 705 & 528 & 528 & 25 \\
\hline DPTSO & 704 & 239 & 352 & 66 \\
\hline
\end{tabular}

aerobic/anaerobic population in microbiological experiments. The biofilm may deposit onto one side of the quartz oscillator whose resonant frequency depends on the vibration mass. As the mass change in this case was supposed to be the consequence of the microbial adhesion, this process was monitored in situ.

The microbes in cooling water can redouble in several hours; the mass change measured by quartz crystal microbalance in the first hour is due to the EPS production and to the first microbial adhesion. It is important to measure the adhesion in the first period as a thick biofilm layer could cause a non-ideal behavior of a non-rigid tick biofilm. Blank experiments helped in elimination of side effects (viscosity and density variation, deposited corrosion products, etc.). $\Delta m$ varied between 5 and $8 \mathrm{ng}$ per $6000 \mathrm{~s}$.

Figs. 6 and 7 summarize the influence of the tested chemicals. Mass changes on metal-electrolyte interface, due to bacterial adhesion, were detected by QCM.
Biocides with hydrophilic and ionic characters decreased the bacterial attachment much more effectively than the hydrophobic type. This might be due to polar and ionic interaction between cell membrane (which is covered by negatively charged exopolymeric substances) and metallic surfaces. The biofilm may behave as a membrane between metal surface and solution where ions can partition. The chemicals do not interact with gold but they influence the EPS excretion of microbes.

In other set of experiments iron was electrodeposited on the gold surface of the crystal quartz. Bacterial adhesion (in presence or absence of biocides) was in situ monitored. The excess mass formed on the iron surface was not only due to microbial attachments but also to the formation of different iron oxides/hydroxides evolved on the metal surface in corrosion processes. Mass increase measured in the presence of microbes was corrected by the $\Delta$ mass sensed on iron without bacteria.
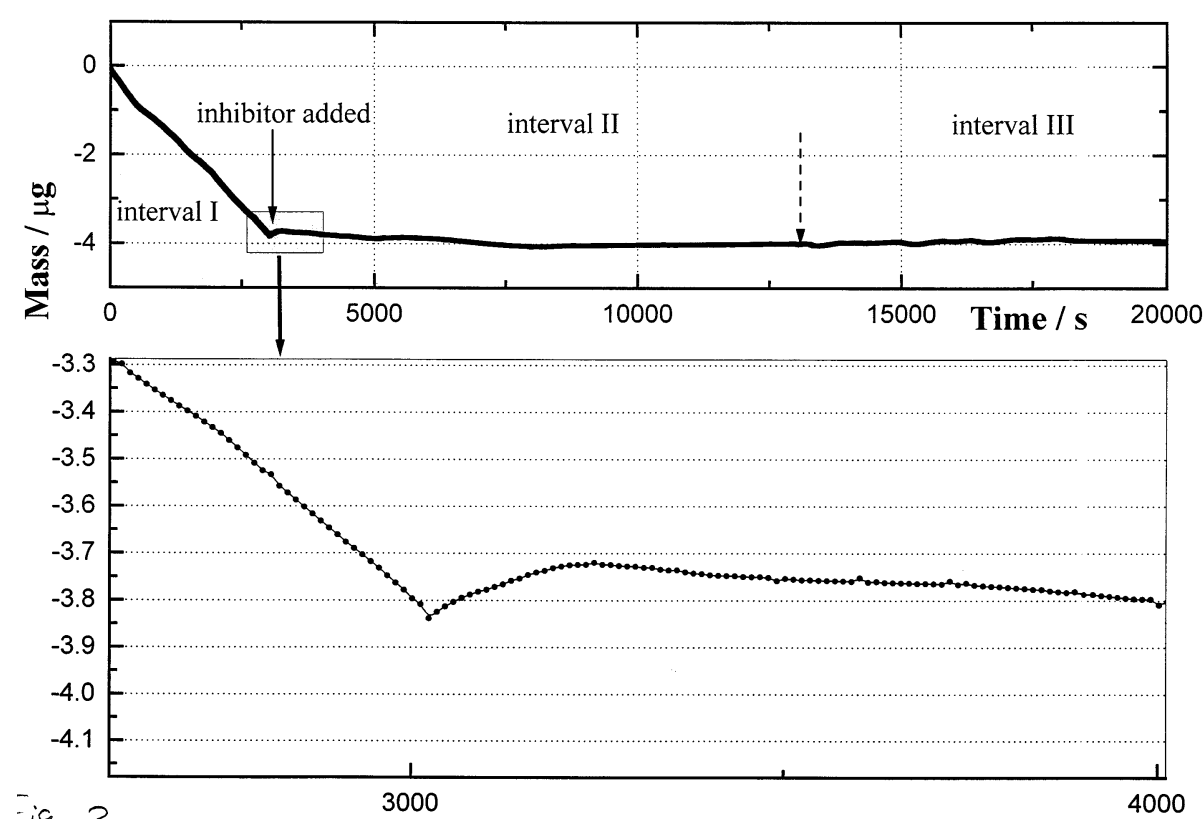

Fig. 3. Frequency change of copper electrode in $0.1 \mathrm{M} \mathrm{Na}_{2} \mathrm{SO}_{4}$ solution, $\mathrm{pH} 2.95$, without and with the addition of $5 \times 10^{-4} \mathrm{M}$ of 5 -McPhTT. 


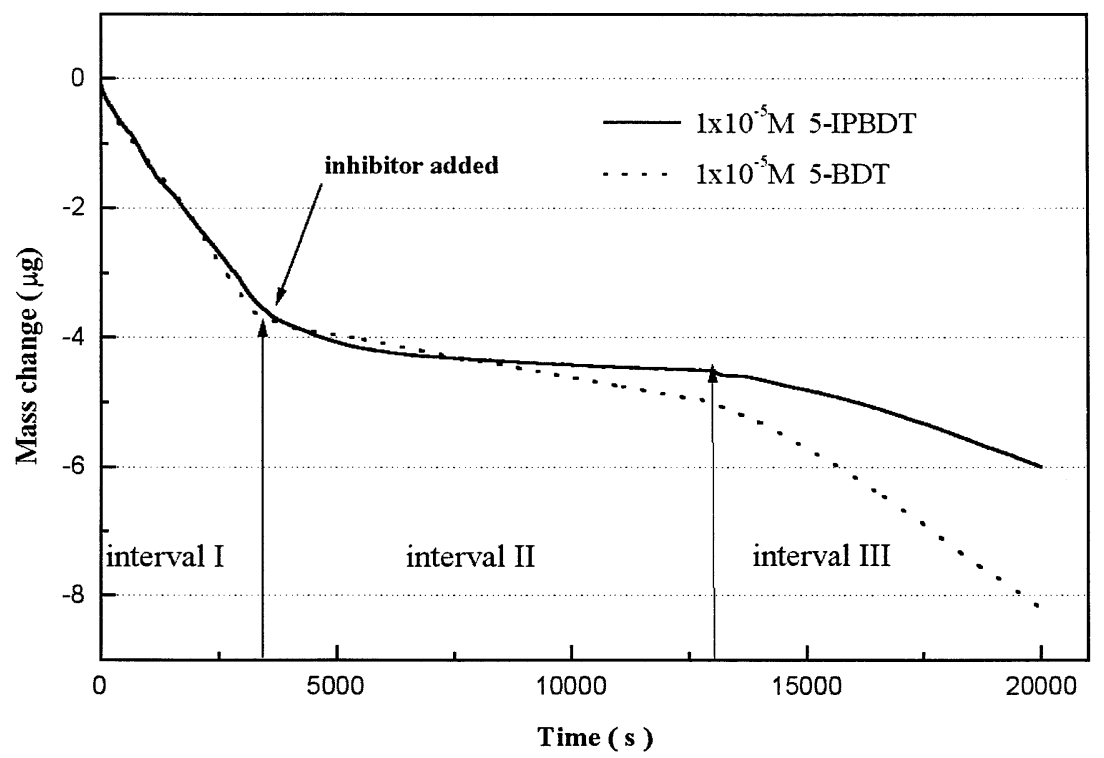

Fig. 4. Time dependence of mass changes of copper electrode in $0.1 \mathrm{M} \mathrm{Na}_{2} \mathrm{SO}_{4},(\mathrm{pH} 2.95)$, without and with the addition of $1 \times 10^{-5} \mathrm{M}$ of 5-BDT and 5-IPBDT, at room temperature.

Table 2

Thickness reduction rate of copper electrode in $0.1 \mathrm{M} \mathrm{Na}_{2} \mathrm{SO}_{4}\left(\mathrm{pH} 2.95\right.$ ), with and without the addition of $1 \times 10^{-5} \mathrm{M}$ of 5 -IPBDT or 5-BDT

\begin{tabular}{|c|c|c|c|c|}
\hline \multirow[t]{2}{*}{ Solution } & \multicolumn{3}{|c|}{ Thickness reduction rate $(\mu \mathrm{m} /$ year $)$} & \multirow[t]{2}{*}{ IE $(\%)$} \\
\hline & Interval I & Interval II & Interval III & \\
\hline 5-IPBDT & 124 & 16 & 24 & 88 \\
\hline 5-BDT & 125 & 20 & 52 & 82 \\
\hline
\end{tabular}

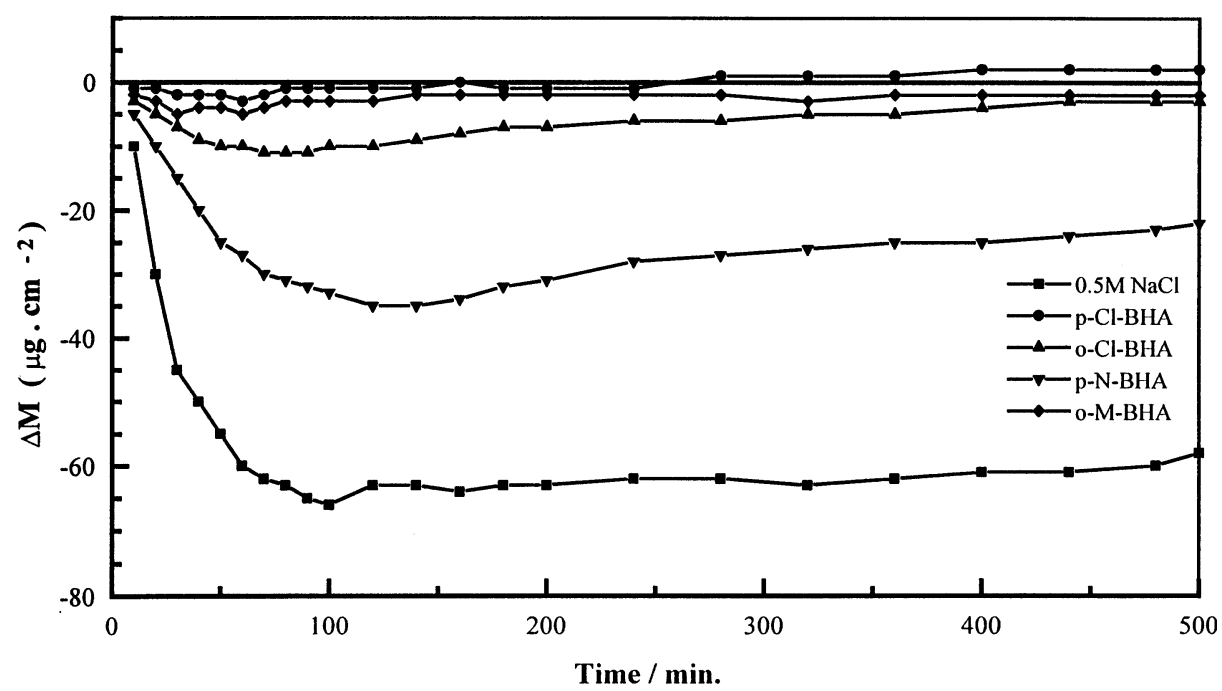

Fig. 5. Time dependence of mass changes of copper electrode in $0.5 \mathrm{M} \mathrm{NaCl}(\mathrm{pH} 6.5)$, solution without and with the addition of $1 \times 10^{-3} \mathrm{M}$ of different benzohydroxamic acid derivatives, at room temperature. 
Results summarized in Fig. 8, show that the quartz crystal microbalance was successfully applied to measure the microbial adhesion and to monitor the inhibited attachment on iron surface as well. The rate of adhesion is much higher on iron than on gold, which is the

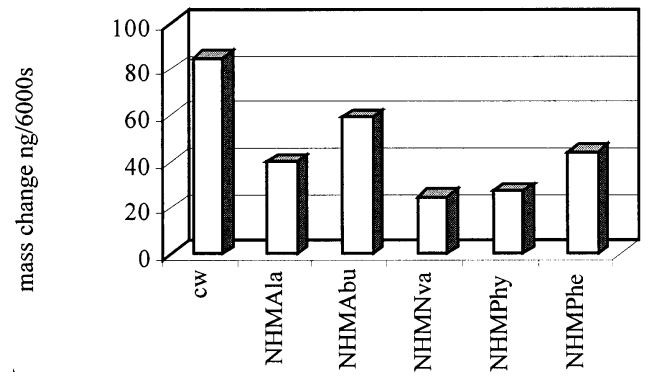

Fig. 6. Inhibition of bacterial adhesion by biocides with hydrophobic side chain. Biocides: NHMAla, $N$-hydroximethylatedalanine; NHMAbu, $N$-hydroxymethylated- $\alpha$-amino butyric acid; NHMNva, $N$-hydroximethylated-norvaline; NHMPhy, $N$-hydroximethylated-phenylglycine; NHMPhe, $N$-hydroximethylated-phenylalanine; cw, cooling water.

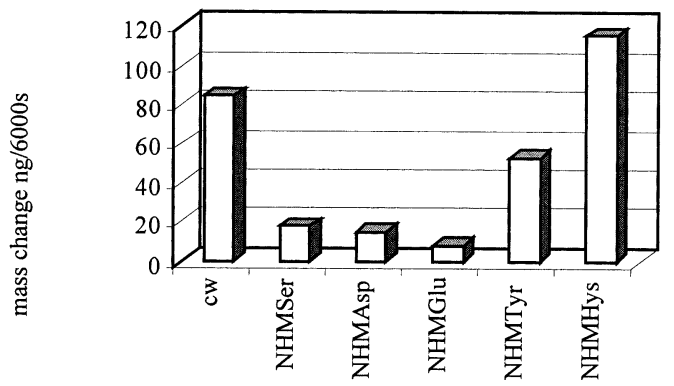

Fig. 7. Inhibition of bacterial adhesion by biocides with heteroatom. Biocides: NHMSer, $N$-hydroximethylated-serine; NHMAsp, $N$-hydroximethylated-aspartic acid; NHMGlu, $N$ hydroximethylated-glutamic acid; NHMTyr, $N$-hydroximethylated-tyrosine; NHMHys, $N$-hydroxymethylated-hystidine; cw, cooling water.

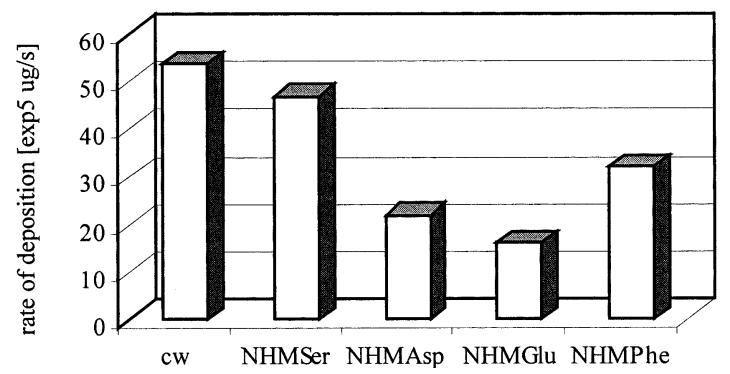

Fig. 8. Inhibition rate of bacterial adhesion on deposited iron surface by biocides. Biocides: NHMSer, $N$-hydroximethylatedserine; NHMAsp, $\quad N$-hydroximethylated-aspartic acid; NHMGlu, $N$-hydroximethylated-glutamic acid; NHMPhe, $N$ hydroximethylated-phenylalanine; cw, cooling water. consequence of the much rougher surface of the freshly deposited iron.

Results obtained by QCM and microbiological and gravimetric methods were compared. The selected chemicals inhibited successively the most important processes in the microbial life at the same time: the bacterial growth, multiplication and the bacterial adhesion. These biocides were the $N$-hydroximethyl derivatives of the serine and glutamic acid.

\section{Conclusions}

EQCM proved to be a powerful tool for in situ characterization of interfacial processes occurring prior to, during, or after corrosion processes.

In the case of copper corrosion inhibition, in addition to inhibition efficiency, penetration rate, which is of practical importance, was also determined. Information on type of film formed could be obtained, where differentiation between 2-D or 3-D films could be made.

Among the sulfoxides, DBSO produced the best protection against copper corrosion in acidic solutions. 5-IPBDT and 5-McPhTT showed excellent inhibition properties in hindering copper corrosion in acidic sulfate containing solutions. In neutral media, $p$-Cl-BHA proved to be the most efficient among the tested BHAs.

QCM technique allowed both monitoring the rate of biofilm formation in real-time experiments and quantitative measurements of biocidal effectiveness. On gold surface with increasing hydrophobicity of biocides, efficiency did not increase. On the other hand, the presence of oxygen, as a component of either polar or ionic groups, resulted in much higher efficacy. On iron surfaces, hydrophobic biocides caused less hindrance on bacterial adhesion than biocides containing oxygen in ionic groups.

The QCM technique was successfully applied in monitoring early stages of biofilm formation (in presence or absence of biocides) whose influence on the microbial deterioration is most important. In combination with other techniques we could choose the most effective biocides that not only decreased the bacterial growth and proliferation, but the microbial adhesion, too.

\section{Acknowledgements}

This work was supported by the National Research Foundation (OTKA) No. T019783, No. T020792, T022507, and T022013.

\section{References}

[1] G. Sauerbrey, Z. Phys. 155 (1959) 206.

[2] M.D. Ward, D.A. Buttry, Science 249 (1990) 1000. 
[3] J.L. Jones, J.P. Meiure, Anal. Chem. 41 (1969) 484.

[4] T. Nomura, M. Ijima, Anal. Chim. Acta 97 (1981) 131.

[5] S. Bruckenstein, M. Shay, Electrochim. Acta 30 (1985) 1295.

[6] M. Beje, M. Eiermann, U. Pitterman, et al., Ber. BunsenGes. Phys. Chem. 90 (1986) 435.

[7] S. Bourkane, C. Gabrielli, M. Keddam, Electrochim. Acta 34 (1989) 1081.

[8] E. Müller, Praktikum der Electrochemie, Stein-Kopp Verlag, 1953.

[9] S. Bruckenstein, S. Swathirajan, Electrochim. Acta 30 (1985) 851.

[10] H.J. Schmidt, U. Pittermann, H. Schneider, et al., Anal. Chim. Acta 273 (1993) 561.

[11] A. Jardy, A. Legal Lasalle-Mulin, M. Keddam, et al., Electrochim. Acta 37 (1992) 2195.
[12] D.J. Jobe, J. Sell, H.W. Pickering, et al., J. Electrochem. Soc. 142 (1995) 2170.

[13] M. Hepel, Proceedings of the 47th ISE Meeting, Balatonfüred, Hungary, 1996, pp. 6a.

[14] M. Fonsati, F. Zucchi, G. Trabanelli, Electrochim. Acta 44 (1998) 311.

[15] M.K. Patterson, G.R. Husted, A. Rutkowski, et al., Ultrapure Water 8 (1991) 18.

[16] W.G. Charaklis, in: W.G. Charaklis, K.C. Marshall (Eds.), Biofilms, Wiley, New York, 1990, p. 671.

[17] T.J. Marrie, M.N. Noble, J.W. Costerton, J. Clin. Microbiol. 18 (1983) 1388.

[18] M. Gryte, M.D. Ward, W.Sh. Hu, Biotechnol. Prog. 9 (1993) 105.

[19] D.E. Nivens, J.Q. Chambers, T.R. Anderson, et al., Anal. Chem. 65 (1993) 65. 